\title{
The Study of Optimal Molding of a LED Lens with Grey Relational Analysis and Molding Simulation
}

\author{
Min-Wen Wang ${ }^{1}$, Fatahul Arifin ${ }^{1,2^{*}}$, Van-Hanh Vu ${ }^{3}$ \\ 1 Department of Mechanical Engineering, National Kaohsiung University of Science and Technology, \\ 415 Jiangong Rd, Kaohsiung 80778, Taiwan \\ 2 Department of Mechanical Engineering, Politeknik Negeri Sriwijaya, \\ Srijaya Negara Rd, Bukit Besar, Palembang 30139, Indonesia \\ ${ }^{3}$ Institute of Mechanical and Precision Engineering, National Kaohsiung University of Applied Sciences \\ 415 Jiangong Rd, Kaohsiung 80778, Taiwan \\ *Corresponding author, e-mail: farifinus@yahoo.com
}

Received: 22 October 2018, Accepted: 28 May 2019, Published online: 23 August 2019

\begin{abstract}
Injection molding technology is known as the most widely used method in mass production of plastic products. To meet the quality requirements, a lot of methods were applied in optimization of injection molding process parameter. In this study the optimization based on Taguchi orthogonal array and Grey relational analysis (GRA) is used to optimize the injection molding process parameters on a LED lens. The four process parameters are: packing pressure, injection speed, melt temperature and mold temperature. The multiresponse quality characteristics are total displacement, volumetric shrinkage, and thermal residual stress. The optimal molding parameters are packing pressure $(90 \mathrm{MPa})$, injection speed $(300 \mathrm{~mm} / \mathrm{sec})$, melt temperature $\left(270{ }^{\circ} \mathrm{C}\right)$ and mold temperature $\left(90{ }^{\circ} \mathrm{C}\right)$. The luminous uniformity of the LED is $92.61 \%$ and the viewing angle of the LED is $124.76^{\circ}$. Among the four factors, packing pressure plays the key role in reducing total displacement, volumetric shrinkage, and thermal residual stress.
\end{abstract}

Keywords

injection molding, LED lens, Taguchi orthogonal array, grey relational analysis, analysis of variance

\section{Introduction}

Nowadays plastic parts become more popular and critical in modern engineering applications, the demand for plastics product quality has increased as well. Injection molding is one of the most effective techniques used in the manufacturing for mass production of plastics parts. The principle of injection molding is very simple. Molten polymer is injected through runner system into a closed mold cavity. Then the molten polymer is cooled and becomes solid. After that the product will be ejected and a molding cycle is repeated. The requirements of molding products compose of many quality facets such as mechanical properties, dimension accuracy, surface quality, optical properties etc. To meet the demand of product quality, it is necessary to consider factors such as plastic materials, part and mold design, mold machining, machine performance and molding process. In these factors, injection molding process has a significant influence on the part's productivity, quality and cost.
The main molding parameters are packing pressure, injection rate, injection pressure, mold temperature, melt temperature, and cooling time. Each parameter influences the quality of the part.

LED is applied in many fields of life as well as in the industry. The typical applications can be categorized as follows: decorative, reading lights, portable, architectural detail, appliance sign and channel letter, cave lighting, household appliance, automotive exterior, LCD backlight, and garden lighting. For different utilization, different lenses should be designed to comply the specific requirements.

Depending on the purposes, there are diverse types of LED lens designs. According to the LED optical distribution curves, there are four common types of LEDs and they are lambertian, batwing, side emitting, and focusing types.

Injection molding technology is known as the most widely applied method in mass production of plastic products. Injection molding produces highly accurate 
products in a fast cycle time. It is one of the most important polymer-processing operations in plastics industry [1]. Many methods have been applied in the optimization of injection molding process parameters. Previously, production engineers used either trial-and-error or Taguchi method to determine optimal process parameter settings. However, these methods are becoming unsuitable in present plastic injection molding industry due to the increasing of part complexity and the needs of multi-objective quality characteristics.

Many researchers used Taguchi method in optimizing shrinkage and warpage of injection molded parts. Erzurumlu and Ozcelik [2] minimized shrinkage and sink marks by using Taguchi method. Tang et al. [3] used Taguchi method to reduce warpage in plastic injection molding. Wang et al. [4] employed Moldex3D in the micro injection molding to produce Blu-ray pick up lens and to find the optimum combination injection molding process using Taguchi experimental method. However, the limitation of Taguchi method is that Taguchi method only has the most effectiveness in optimization one quality characteristic.

Kuo et al. [5] studied the Grey relational analysis to obtain the optimal parameters for polyether ether ketone injection molding process. Kitayama et al. [6] applied multi objective optimization in plastic injection molding process for minimizing warpage, clamping force and cycle time. They used radial basis function network to determine the optimal process parameters and radar chart to perform the trade-off analysis among three objective functions. They found conformal cooling channel can reduce $43 \%$ warpage, $1.7 \%$ clamping force and $47 \%$ cycle time. Lee et al. [7] used multi criteria decision analysis in injection molding of polymeric microcellular nanocomposite foams containing multi walled carbon nanotubes (MWCNTs). They found that the optimum process parameters are $1 \mathrm{wt} \%$ of MWCNT, holding pressure time of $4 \mathrm{~s}$ and holding pressure of $100 \mathrm{MPa}$.

Haq et al. [8] studied the multiple response optimization of machining parameters of drilling $\mathrm{Al} / \mathrm{SiC}$ metal matrix composite using grey relational analysis in the Taguchi method. Tzeng et al. [9] also applied Taguchi method and Grey relational analysis in optimization of multi response quality characteristics for turning operations. Panda et al. [10] used the Grey relational analysis combined with Taguchi method to optimize the parameters in hard turning using ceramic insert. Their results proved this methodology was efficient for solving multi attribute decision making problem as a case study in hard machining environment. Sofuoglu [11] used Taguchi method with Reference
Ideal Method to solve the machining problem. Sofuoglu and Orak [12] applied the Best-Worst method hybridized with TOPSIS, Grey Relational Analysis, and Weighted Sum Approach in turning operation. The results of both [11, 12] showed the combination of multi criteria decision making can be applied by operator and engineering in the manufacturing environment. Sofuoglu et al. [13] also applied five different hybrid multi-criteria decision making models in different cutting conditions in turning operation. Their result showed cutting parameters are optimized by maximizing material removal rate and minimizing cutting force and surface roughness. Sivam et al. [14] applied Grey relational analysis and ANOVA in multi response optimization of setting input variable for getting better product quality in machining of magnesium AM60, the expected response and measured response are fairly close in the study. Sivam et al. [15] also studied the friction stir welding of Ti and $\mathrm{Mg}$ alloys by using Taguchi method, Grey relational analysis and ANOVA approaches to determine the optimum process parameters. Their results showed that the measured values are close to the expected values.

LEDs are everywhere in the world for lighting and display applications, small and even micro lenses are often used to mount on the LED chips to obtain the desired light distribution patterns. Fig. 1 shows a micro lens designed for high viewing angle and high luminous uniformity LED application. Detriments of the lens qualities from the original design are inevitable after molding. To reduce the detriments, the molding process should consider volumetric shrinkage, total displacement, and thermal residual stress of the molded micro lens. Compared with Taguchi method which is usually applied to find the best molding parameter for single objective, the grey-based Taguchi method is better in finding the optimal process parameters with multiple quality characteristics. Instead of Taguchi Method, Taguchi orthogonal array and Grey relational analysis integrated with molding simulation using Modex3D will be implemented in this study to discover the best injection molding parameters of the micro lens to achieve both high viewing angle and high luminous uniformity.

\section{Lens design, mold design and injection molding simulation}

\subsection{Lens design}

\subsubsection{Original lens}

The lens investigated in this study is designed by Chen et al. [16]. Both the dimensions and the shape of the lens were designed to obtain the largest viewing angle and 

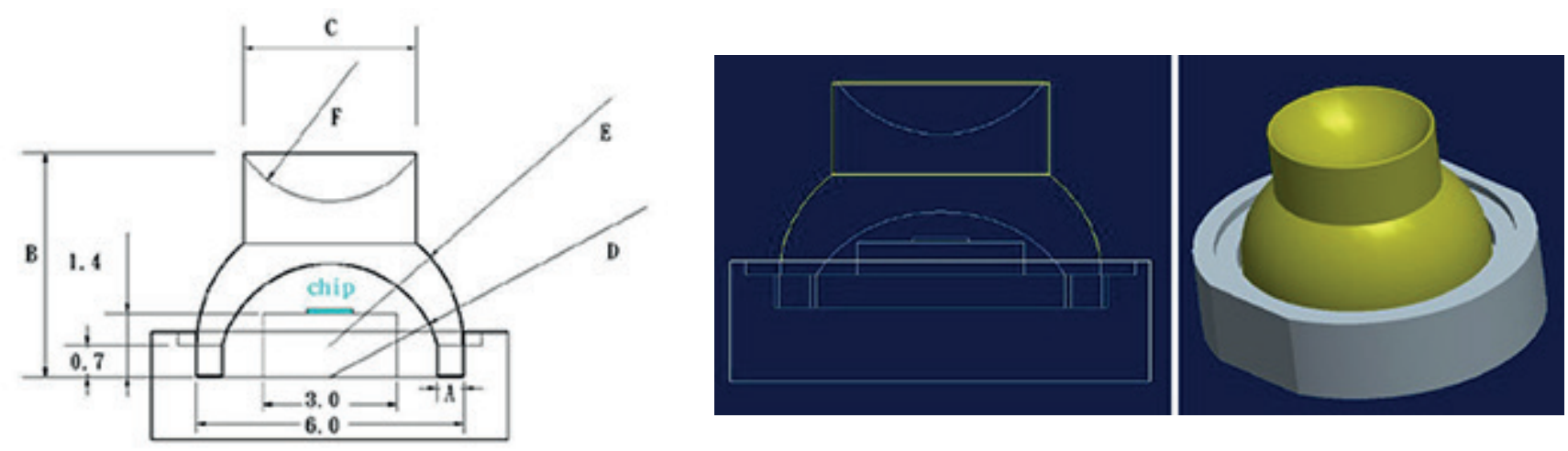

Fig. 1 Original Lens design and LED base

highest candela uniformity. The shape and dimensions of the lens are shown in Table 1 and Fig. 1.

With Chen et al. [16] optimal design, the viewing angle of $130^{\circ}$ and the uniformity up to $93.35 \%$ is able to be achieved. However, all of lens dimensions have many digits behind decimal mark and it is not worthwhile in making of the lens with such high accuracy. Then, the lens dimensions should be modified to more reasonable and acceptable dimensions by the mold makers. In this study, the dimensions are rounded to two digits after decimal point, and all the fillet radii of rounded corners are $0.05 \mathrm{~mm}$.

The optical simulation is run using TracePro software again with the modified dimensions of the lens to find out the viewing angle and the luminous uniformity. The new dimensions are acceptable when the optical simulation result is close enough to the original design. The result of optical simulation consists of polar and rectangle Candela distribution as can be seen in Fig. 2, and the view angle and luminance uniformity are $129.2^{\circ}$ and $94.14 \%$, respectively.

\subsubsection{Modifying the lens dimensions}

\subsubsection{Method I}

For each dimension, if the third digit standing behind the decimal mark is bigger or equal to 5 , the dimension will be rounded up to the second digit. Inversely, if the third digit is smaller than 5 , the dimension will be rounded off to the second digit behind the decimal mark. Therefore, the dimensions are listed in Table 2.

Dimension B is smaller due to the rounded edge with fillet radius $r=0.05 \mathrm{~mm}$.

\subsubsection{Method II}

Just preserve the first two digits behind the decimal mark and ignore the rest digits (Table 3).

\subsubsection{Hybrid method}

In the preceding methods, $\mathrm{A}$ is rounded up and $\mathrm{C}$ is rounded off. However, the third digits of dimensions $\mathrm{A}$ and $\mathrm{C}$ behind the decimal mark are very close to 5 . If these digits are modified in another way, it might also

Table 1 Lens dimensions in $\mathrm{mm}$

\begin{tabular}{cccccc}
\hline $\mathrm{A}$ & $\mathrm{B}$ & $\mathrm{C}$ & $\mathrm{D}$ & $\mathrm{E}$ & $\mathrm{F}$ \\
\hline 0.66598 & 5.05183 & 3.89423 & 2.51083 & 3 & 2.3969 \\
\hline
\end{tabular}

Table 2 Modified dimensions in method I, ( $\mathrm{mm}$.)

\begin{tabular}{lcccccc}
\hline & $\mathrm{A}$ & $\mathrm{B}$ & $\mathrm{C}$ & $\mathrm{D}$ & $\mathrm{E}$ & $\mathrm{F}$ \\
\hline Original dimensions & 0.66598 & 5.05183 & 3.89423 & 2.51083 & 3 & 2.3969 \\
Modified dimensions & 0.67 & 4.9 & 3.89 & 2.51 & 3 & 2.36 \\
\hline
\end{tabular}

Table 3 Modified dimensions with method II, (mm.)

\begin{tabular}{lcccccc}
\hline & $\mathrm{A}$ & $\mathrm{B}$ & $\mathrm{C}$ & $\mathrm{D}$ & $\mathrm{E}$ & $\mathrm{F}$ \\
\hline Original dimensions & 0.66598 & 5.05183 & 3.89423 & 2.51083 & 3 & 2.3969 \\
Modified dimensions & 0.66 & 4.91 & 3.89 & 2.51 & 3 & 2.35 \\
\hline
\end{tabular}




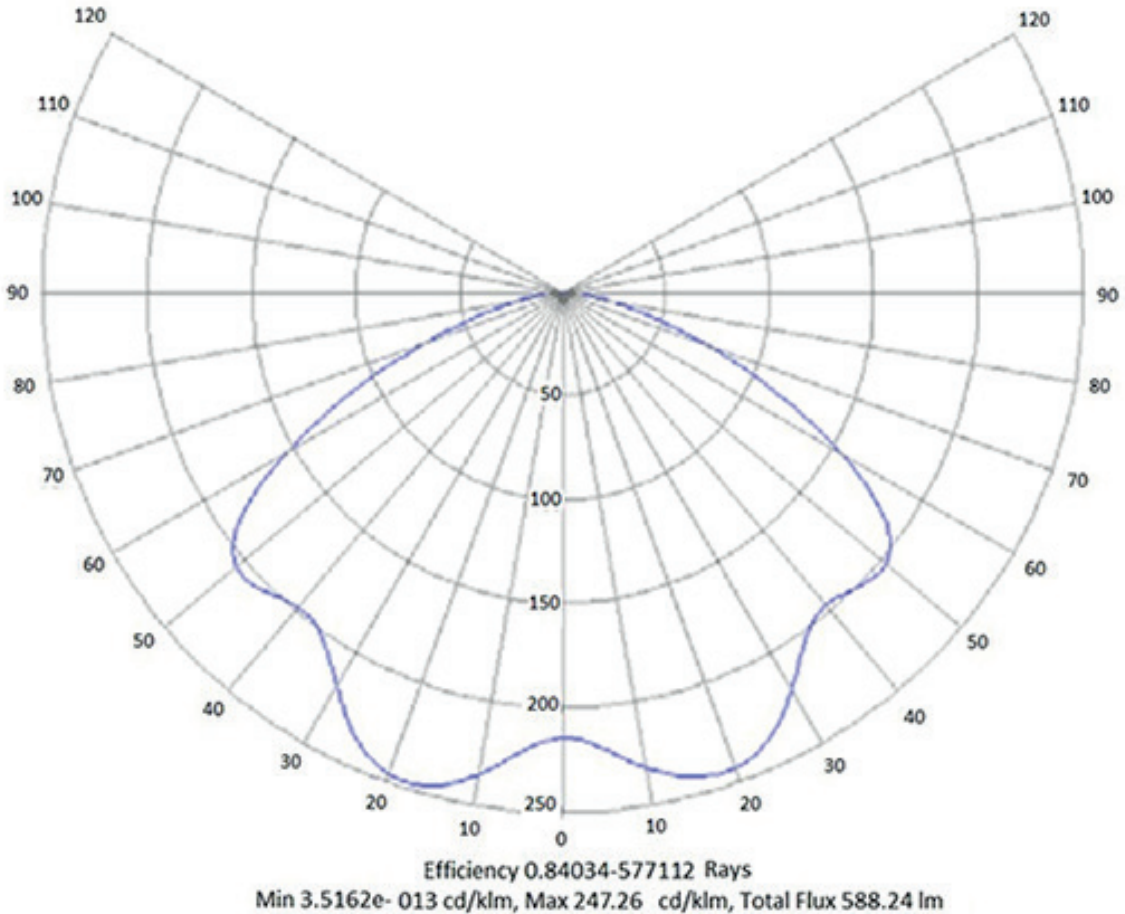

(b)

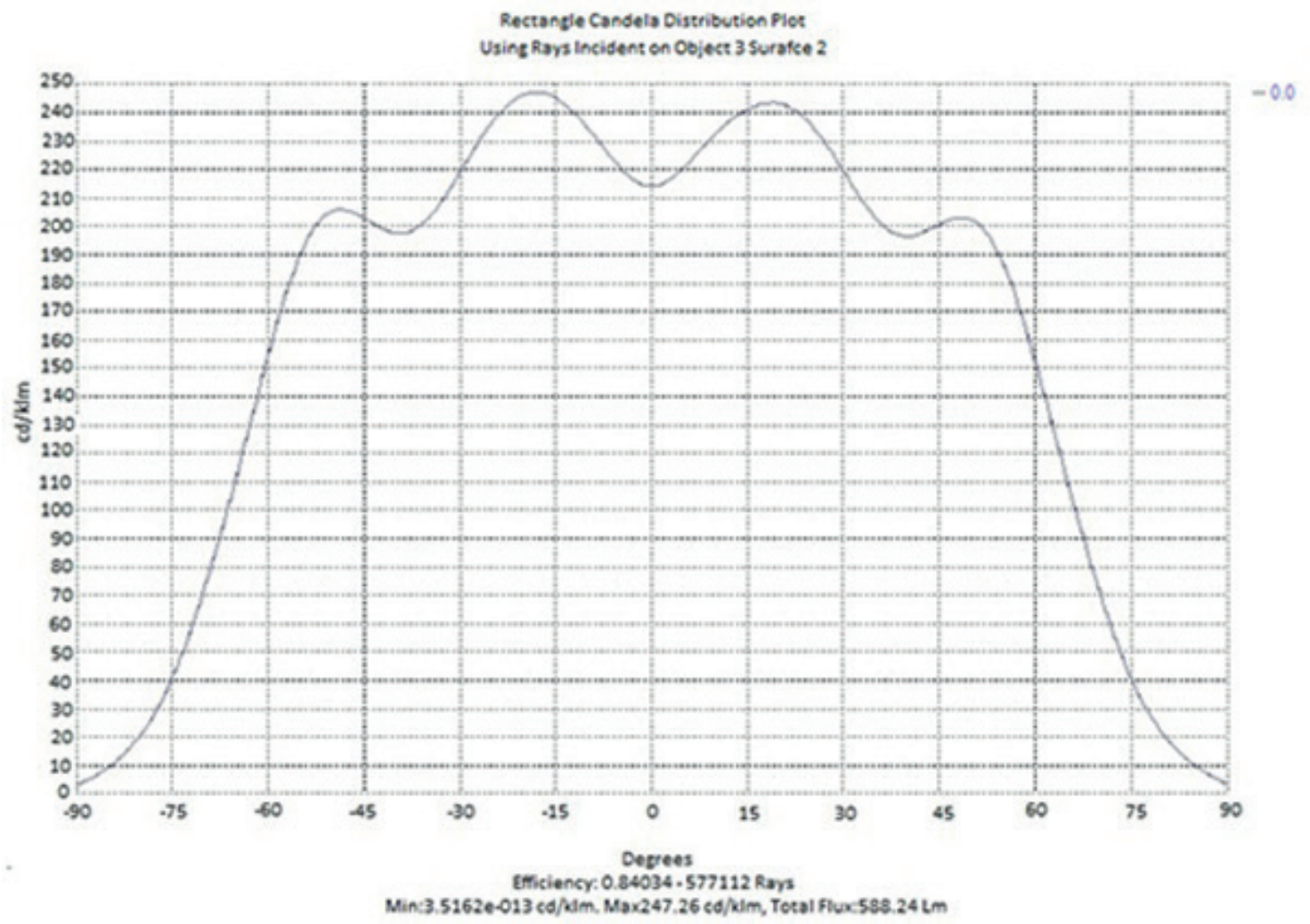

Fig. 2 Distribution plot: (a) Polar Candela (b) Rectangle Candela 
affect the viewing angle and candela uniformity as much as the two methods above. Therefore, a hybrid method which is the combination between the two previous methods are employed. Accordingly, A is rounded off while C is rounded up. Other dimensions were modified using the same principle as the method I. So, the modified dimensions are shown in Table 4.

\subsubsection{Optical simulation and the results of luminous uniformity}

The optical simulation was performed using TracePro software under the following simulation conditions:

- Material of lens: Polymetyl Methacrylate (PMMA), refractive index is 1.4935

- The LED chip dimension is $1 \mathrm{~mm}$ in length, $1 \mathrm{~mm}$ in width, $0.1 \mathrm{~mm}$ in height

- Applying the surface sources for LED chip with the luminous flux:

- + Top face: $500 \mathrm{~lm}$ and 400,000 light rays.

- + 4 side faces: $50 \mathrm{~lm}$ and 40,000 light rays.

- The distance from the inspection plane to the base of LED is $10 \mathrm{~mm}$.

The luminance uniformity $(u)$ is the averaged luminance of all the values of troughs and crests of the four luminance distribution curves measured at azimuth angles $0^{\circ}, 45^{\circ}$, $90^{\circ}$, and $135^{\circ}$, and its show in Eq. (1) and Eq. (2) [16]:

$y=\frac{1}{n} \sum_{i=1}^{n} y_{i}$

$u=\left[1-\frac{\frac{1}{n} \sum_{i=1}^{n}\left|y_{i}-\bar{y}\right|}{\bar{y}}\right] \times 100 \%$.
Where, $y_{i}$ is the values of troughs and crests in the luminance distribution curves, $n$ is the total occurrence times of troughs and crests of the four curves, $\bar{y}$ is the mean value of crests and troughs values. In addition, the LED viewing angle is the averaged full width half at maximum angles measured from the 4 different azimuth luminance distribution curves. The optical simulations results are showed in Table 5.

According to the trial results above, we choose the one that have the highest value in viewing angle $\left(129.2^{\circ}\right)$ and luminance uniformity $(94.14 \%)$. The final dimensions of the lens are showed in Table 6.

\subsection{Mold design}

A two-plate 4-cavity mold is designed for the molding simulation of the lens. Fig. 4 shows the schematic drawing of the mold, the runner system, the 4 cavities and the cooling system that are designed for molding this LED lens using a FANUC ROBOSHOT S-200i50B injection molding machine.

Some specifications of the machine are screw diameter $22 \mathrm{~mm}$, screw stroke $75 \mathrm{~mm}$, maximum shot weight 29 grams, maximum injection rate $125 \mathrm{~cm}^{3} / \mathrm{sec}$, maximum injection pressure $260 \mathrm{MPa}$ and clamping force 50 ton. The parting line is located close to the bottom of the part.

The edge type gate is chosen in this study (see Fig. 5). The gate dimension is $0.4 \mathrm{~mm}$ in thickness, $1 \mathrm{~mm}$ in length, and $1 \mathrm{~mm}$ in width.

\subsection{Injection molding simulation}

In this study, Moldex3D was employed to study the mold filling process. The PMMA GH-1000S grade (Kuraray, Japan) is chosen as the lens material. The PvT diagram

Table 4 Modified dimensions with hybrid method, (mm.)

\begin{tabular}{lcccccc}
\hline & $\mathrm{A}$ & $\mathrm{B}$ & $\mathrm{C}$ & $\mathrm{D}$ & $\mathrm{E}$ & $\mathrm{F}$ \\
\hline Original dimensions & 0.66598 & 5.05183 & 3.89423 & 2.51083 & 3 & 2.3969 \\
Modified dimensions & 0.66 & 4.91 & 3.9 & 2.51 & 3 & 2.36 \\
\hline
\end{tabular}

Table 5 The optical simulation results

\begin{tabular}{lcc}
\hline Method & $\begin{array}{c}\text { The Luminance } \\
\text { Uniformity }(\%)\end{array}$ & $\begin{array}{c}\text { The Viewing } \\
\text { Angle }\left({ }^{\circ}\right)\end{array}$ \\
\hline I & 92.56 & 127.8 \\
II & 93.86 & 129.19 \\
Hybrid & 94.14 & 129.2 \\
\hline
\end{tabular}

Table 6 Final dimensions of the modified lens

\begin{tabular}{cccccc}
\hline $\mathrm{A}$ & $\mathrm{B}$ & $\mathrm{C}$ & $\mathrm{D}$ & $\mathrm{E}$ & $\mathrm{F}$ \\
\hline 0.66 & 4.91 & 3.9 & 2.51 & 3 & 2.36 \\
\hline
\end{tabular}



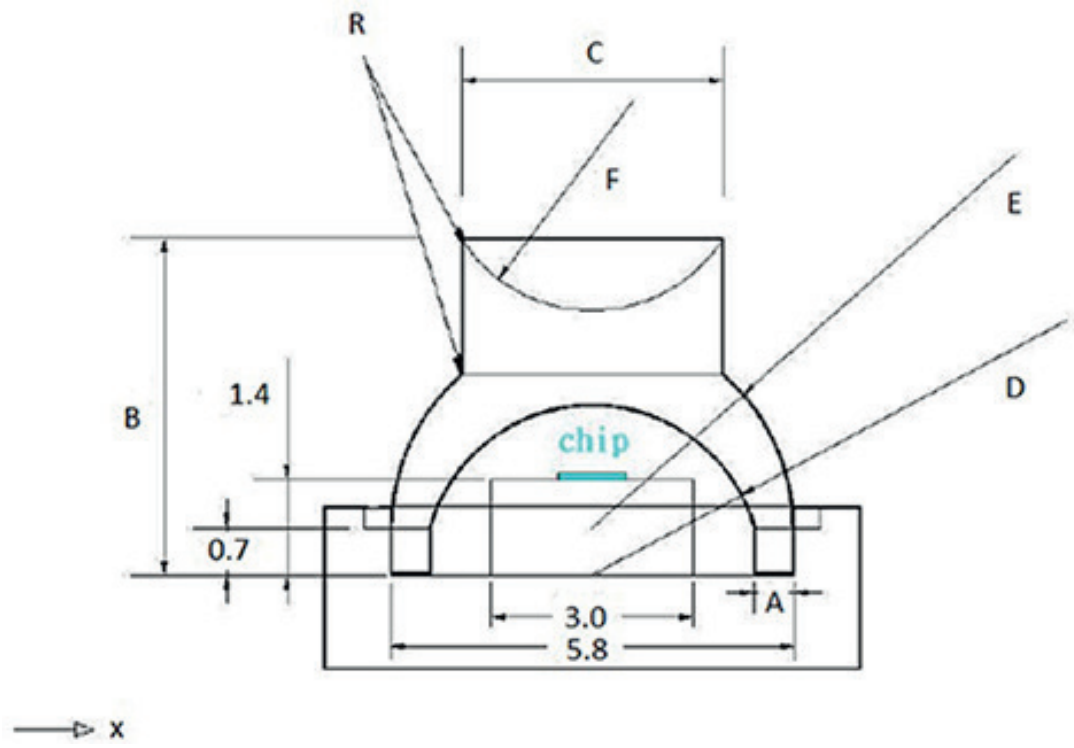

Fig. 3 Schematic of the new lens

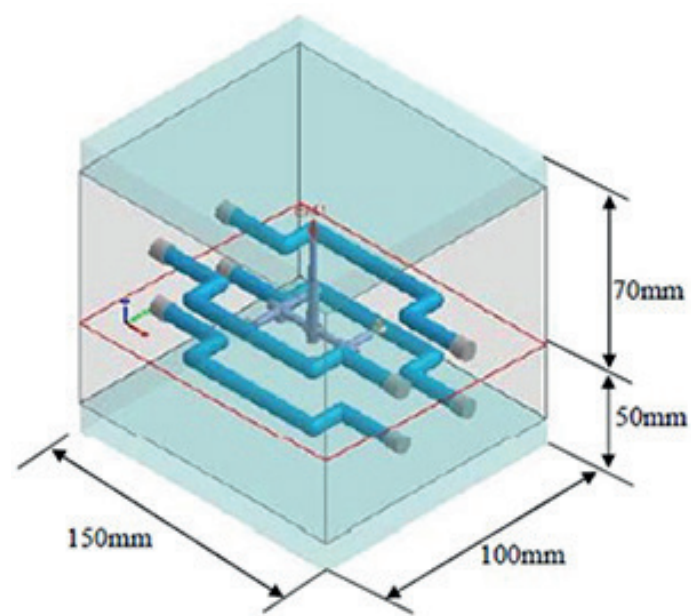

Fig. 4 Schematic picture of the mold system

and the shear viscosity curve of the PMMA material are shown in Figs. 6 and 7. The parameters ranges suggested by Moldex 3D software's library are melt temperature $240{ }^{\circ} \mathrm{C}-295{ }^{\circ} \mathrm{C}$, mold temperature $60{ }^{\circ} \mathrm{C}-95^{\circ} \mathrm{C}$, ejection temperature: $100^{\circ} \mathrm{C}$, and freeze temperature $120^{\circ} \mathrm{C}$.

\section{Design parameters analysis}

\subsection{Overview of parameter design process}

Some researchers have used different processing factors in the optimization of injection molding parameters. Tang et al. [3] has reduced the warpage of plastics product by optimizing the values of four factors: melt temperature, filling time, packing time, and packing pressure. Altan [17] used four factors including melt temperature, injection pressure, packing pressure, and packing time to

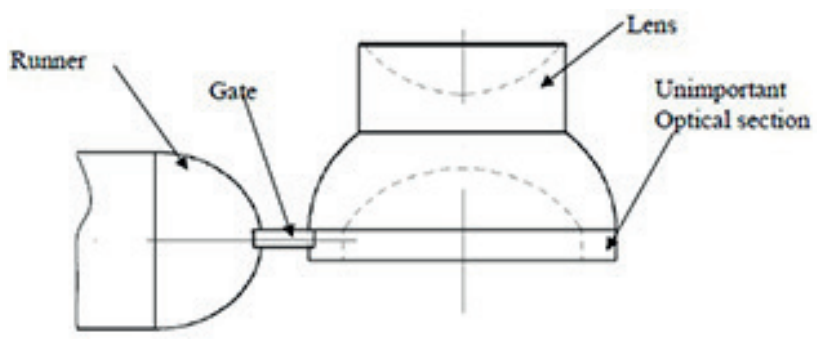

Fig. 5 Schematic drawing of gate, runner and cavity

reduce shrinkage in injection molding. Oktem et al. [18] also reduced shrinkage and warpage of a thin-shell part by determining five process parameters consisting of melt flow index, injection velocity, mold temperature, melt temperature, and injection pressure.

Based on the previous studies it can be concluded that processing factors affecting the injection molding quality most are injection speed, packing pressure, mold temperature, and melt temperature. Grey-based Taguchi method has the capability to find the optimal process parameters with multiple quality characteristics such as the lens presented in Fig. 3. This study will implement Taguchi orthogonal array and Grey relational analysis to find the best combination of injection process parameters of the LED lens in this study.

\subsection{Designing the processing windows}

Four factors will be selected to study their effects on the lens's shrinkage and warpage. They are injection speed, packing pressure, mold temperature and melt temperature. Before the optimization process, a processing window for injection 


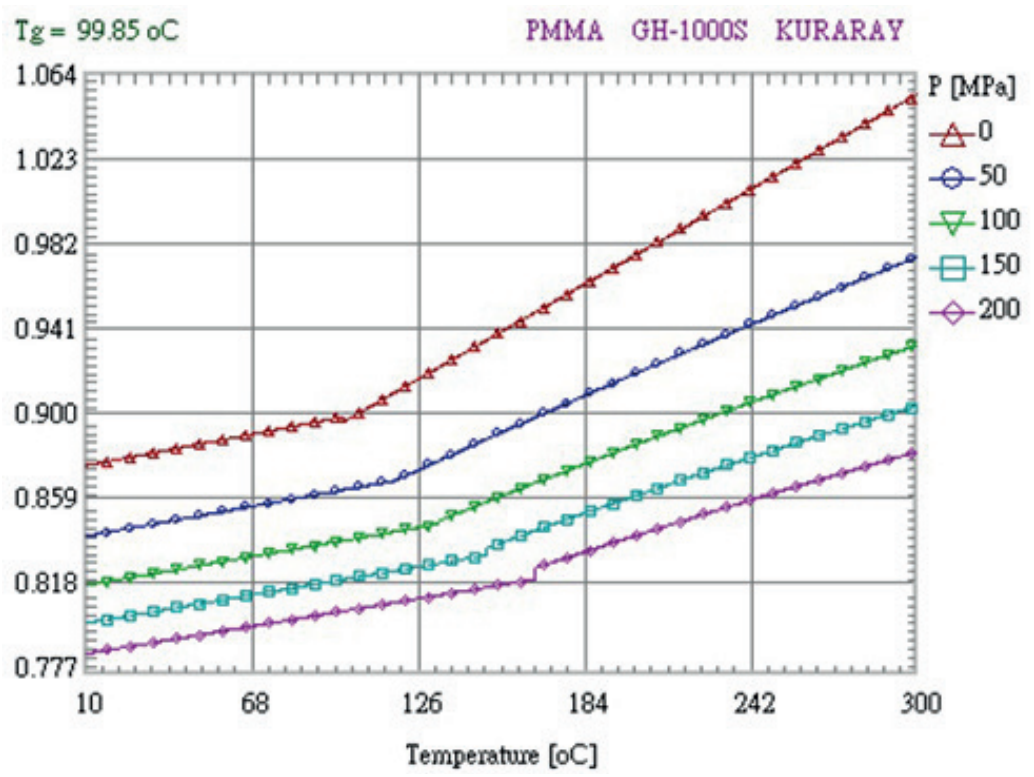

Fig. 6 KURARAY PMMA's PvT diagram

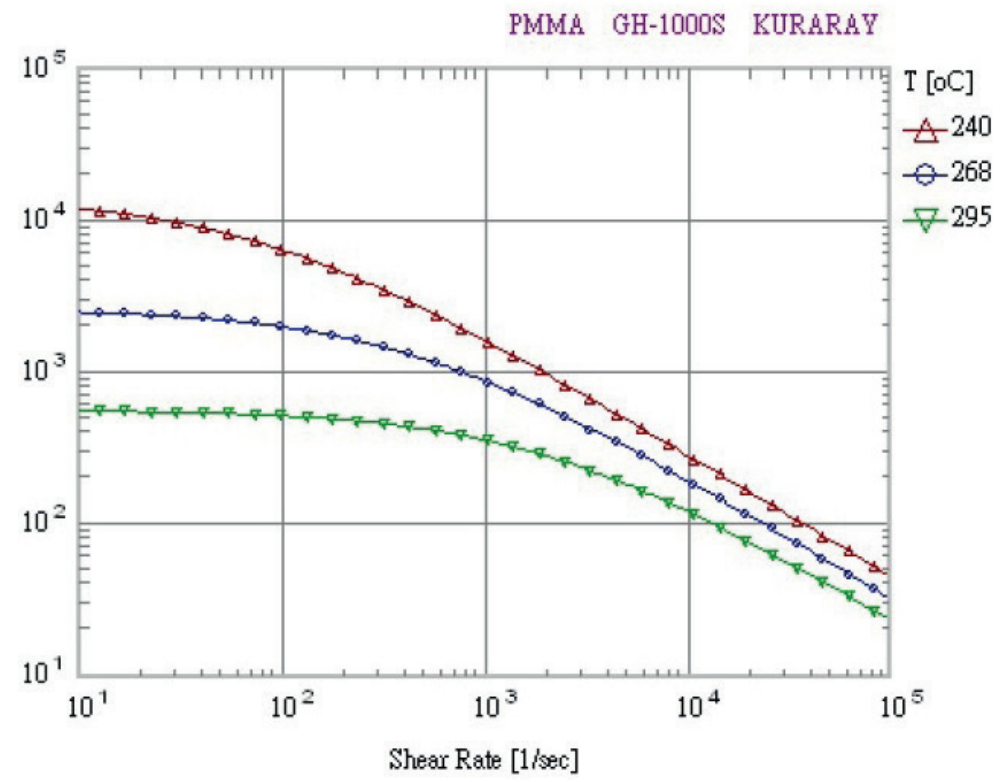

Fig. 7 KURARAY PMMA's shear viscosity curve

speed and packing pressure has been built as shown in Fig. 8. The processing window has been investigated to find out the processable range of the molding parameters. Fig. 8 shows that in the area restricted by injection speed (50 320 $\mathrm{mm} / \mathrm{sec}$ ) and packing pressure (80 95 MPa), the part's quality can be obtained. Too low the injection speed and packing pressure, the shrinkage will be large. On the other hand, too high the injection speed and packing pressure, flash and degradation will occur. The ranges of the melt temperature and mold temperature have been selected according to the suggestions of the plastics suppliers.
The lens volume is $56.434 \mathrm{~mm}^{3}$. So, the molding process is able to be considered as micro-injection molding process. The processing window found through molding simulation suggests that the part is able to be molded from $50 \mathrm{~mm} / \mathrm{sec}$ to $320 \mathrm{~mm} / \mathrm{sec}$. In the optimal experiments, the injection speed range will be set between $280 \sim 300 \mathrm{~mm} / \mathrm{sec}$, choosing the higher bound of the process window is to ensure complete filling of the cavities. The packing pressure range is chosen between $80 \sim 90 \mathrm{MPa}$ in this experiment. 


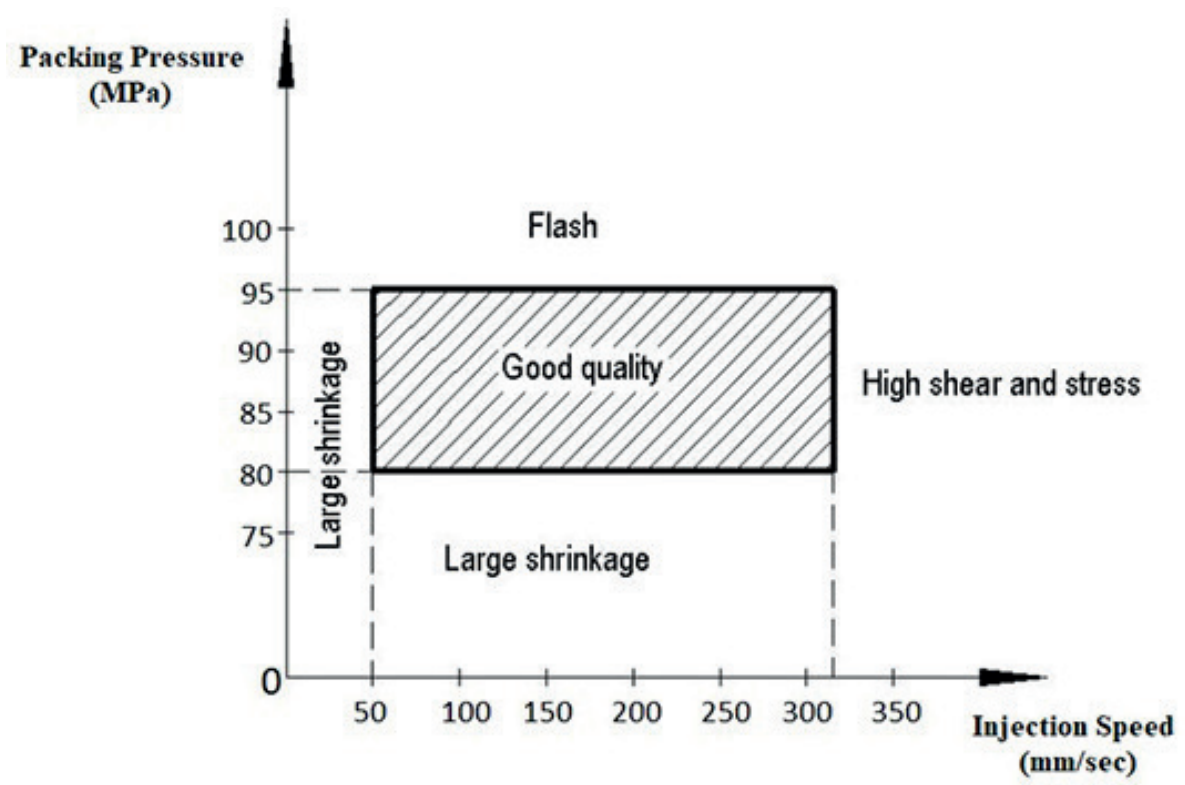

Fig. 8 The lens processing window

\subsection{The control factors}

To have the best optical function from the LED lens, the molded lens should has the contour as close as designed, so the total displacement and volumetric shrinkage of the molding part should be reduced as well as the thermal stress built during molding process. Residual thermal stress tends to induce birefringence of the plastic optical part that should be kept as small as possible. Therefore, the method which integrated Taguchi method and Grey relational analysis will be implemented to minimize the total displacement, volumetric shrinkage, and thermal stress in this study. For this case, four factors are selected to optimize the total displacement, volumetric shrinkage, and thermal residual stress, and they are Injection speed (InS), packing pressure $\left(P_{\text {Press }}\right)$, mold temperature $\left(T_{\text {mold }}\right)$, and melt temperature $\left(T_{m e l}\right)$. The optimization procedure can be divided into two stages. At first, with four control factors and each with three levels, so an $\mathrm{L}_{9}\left(3^{4}\right)$ Taguchi orthogonal array was selected. The parameter levels for the three controls factors are listed in Table 7. Table 8 shows the orthogonal array.

The others parameters remained at fixed in this study are cooling time (15 seconds), packing time ( 3 seconds), ejection temperature $\left(100^{\circ} \mathrm{C}\right)$, and VP switch $(98 \%)$.

Table 7 Factors value and levels in the Taguchi experiments for LED lens injection molding process

\begin{tabular}{|c|c|c|c|c|}
\hline & $\mathrm{InS}(\mathrm{mm} / \mathrm{sec})$ & $P_{\text {Press }}(\mathrm{MPa})$ & $T_{\text {mold }}\left({ }^{\circ} \mathrm{C}\right)$ & $T_{\text {melt }}\left({ }^{\circ} \mathrm{C}\right)$ \\
\hline Level 1 & 280 & 80 & 80 & 270 \\
\hline Level 2 & 290 & 85 & 85 & 280 \\
\hline Level 3 & 300 & 90 & 90 & 290 \\
\hline \multicolumn{5}{|c|}{ Table $8 \mathrm{~L}_{9}\left(3^{4}\right)$ orthogonal array } \\
\hline Exp. & $\operatorname{InS}(\mathrm{mm} / \mathrm{sec})$ & $P_{\text {Press }}(\mathrm{MPa})$ & $T_{\text {mold }}\left({ }^{\circ} \mathrm{C}\right)$ & $T_{\text {melt }}\left({ }^{\circ} \mathrm{C}\right)$ \\
\hline 1 & 280 & 80 & 80 & 270 \\
\hline 2 & 280 & 85 & 85 & 280 \\
\hline 3 & 280 & 90 & 90 & 290 \\
\hline 4 & 290 & 80 & 85 & 290 \\
\hline 5 & 290 & 85 & 90 & 270 \\
\hline 6 & 290 & 90 & 80 & 280 \\
\hline 7 & 300 & 80 & 90 & 280 \\
\hline 8 & 300 & 85 & 80 & 290 \\
\hline 9 & 300 & 90 & 85 & 270 \\
\hline
\end{tabular}


Finally, Grey relational analysis is carried out at the second stage. All three qualities are smaller-the-better for this study. The calculation procedure for the Grey relational analysis is as following [8].

Step 1: Calculate the $\mathrm{S} / \mathrm{N}$ ratio for the corresponding responses using the Eq. (3):

$\eta=-10 \log \left[\frac{1}{n}\right] \sum_{i=1}^{n} y_{i j}^{2}$

where $n=$ number of replication, $y_{i j}=$ observed response value, $i=1,2,3, \ldots n ; j=1,2, \ldots \mathrm{k}$.

Step 2: Normalize the $\mathrm{S} / \mathrm{N}$ ratio values as Eq. (4).

$$
Z_{i j}=\frac{\max \left(y_{i j}, i=1,2, \ldots n\right)-y_{i j}}{\max \left(y_{i j}, i=1,2, \ldots n\right)-\min \left(y_{i j}, i=1,2, \ldots n\right)}
$$

Step 3: Calculate the Grey relational coefficient for the normalized $\mathrm{S} / \mathrm{N}$ ratio values as Eq. (5).

$\gamma\left(\gamma_{0}(k), \gamma_{i}(k)\right)=\frac{\Delta \min +\zeta \Delta \max }{\Delta_{0}(k)+\zeta \Delta \max }$

where;

- $j=1,2, \ldots n ; k=1,2, \ldots m, n$ is the number of experimental data items and $m$ is the number of responses.

- $y_{0}(k)$ is the reference sequence $\left(y_{0}(k)=1, k=1,2, \ldots m\right)$; $y_{j}(k)$ is the specific comparison sequence.

- $\Delta_{0 j}=\left\|y_{0}(k)-y_{j}(k)\right\|$ is the absolute value of the difference between $y_{0}(k)$ and $y_{\mathrm{j}}(k)$

- $\Delta \min =\underset{\forall j e i}{\min } \underset{\forall k}{\min }\left\|y_{0}(k)-y_{j}(k)\right\|$ is the smallest value of $y_{\mathrm{j}}(k)$

- $\Delta \max =\underset{\forall j e i}{\max } \max _{\forall k}\left\|y_{0}(k)-y_{j}(k)\right\|$ is the largest value of $y_{j}(k)$

- $\zeta$ is the distinguishing coefficient, which is defined in the range of 0 to 1 .

Step 4: Generate the Grey relational grade as Eq. (6). $\bar{\gamma}=\frac{1}{k} \sum_{i=1}^{n} \gamma_{j i}$

where $\bar{y}_{j}$ is the Grey relational grade for the $i^{\text {th }}$ experiment and $k$ is the number of performance characteristics.

Step 5: Determine the optimal factor and its level combination. The higher Grey relational grade implies the better product quality.

After calculating the Grey relational grades the optimal factor / level combinations can be found.

\section{Result and discussion}

\subsection{The Taguchi analysis}

4.1.1 Simulation results

After running the simulation with Moldex3D, the data collected namely; the total displacement (TD), the average of volumetric shrinkage (VS) and the thermal residual stress (TRS). Based on the result reports, the output values of quality characteristics have been gathered. The simulation has performed in 9 experiments, the results and the $\mathrm{S} / \mathrm{N}$ responses value are shown in Table 9, and the main effect of $\mathrm{S} / \mathrm{N}$ ratio can be seen in Fig. 9.

\subsubsection{Taguchi Analysis Discussion}

\subsubsection{The total displacement}

Molding part warpage is the results of the total displacement of the injection molded part in comparison with the original model. During molding process, the pressure, temperature, and cooling rate at different locations of the cavity will result in different shrinkage, and displacement. In addition, the thermal-induced residual stress will also cause shrinkage and total displacement as well as birefrigence of the lens. Since the lens molded in this study has difference thickness, it will make this problem even worse.

Table 9 The Results of output values and the $\mathrm{S} / \mathrm{N}$ response value

\begin{tabular}{|c|c|c|c|c|c|c|}
\hline Exp. & $\mathrm{TD}$ & $\mathrm{S} / \mathrm{N}$ TD & VS & $\mathrm{S} / \mathrm{N}$ TDR & TRS & $\mathrm{S} / \mathrm{N}$ TRS \\
\hline 1 & 0.014839 & 36.572 & 0.764112 & 2.337 & 19.5092 & -25.805 \\
\hline 2 & 0.013219 & 37.576 & 0.368178 & 8.679 & 19.8457 & -25.953 \\
\hline 3 & 0.011900 & 38.489 & 0.020936 & 33.582 & 19.7173 & -25.897 \\
\hline 4 & 0.014362 & 36.856 & 0.563840 & 4.977 & 20.6064 & -26.280 \\
\hline 5 & 0.013391 & 37.464 & 0.464489 & 6.660 & 19.3358 & -25.727 \\
\hline 6 & 0.012106 & 38.340 & 0.079634 & 21.978 & 19.6733 & -25.877 \\
\hline 7 & 0.014433 & 36.813 & 0.649570 & 3.747 & 19.7351 & -25.905 \\
\hline 8 & 0.013063 & 37.679 & 0.261561 & 11.648 & 20.4242 & -26.203 \\
\hline 9 & 0.012034 & 38.392 & 0.164248 & 15.690 & 18.7499 & -25.460 \\
\hline
\end{tabular}


(a)

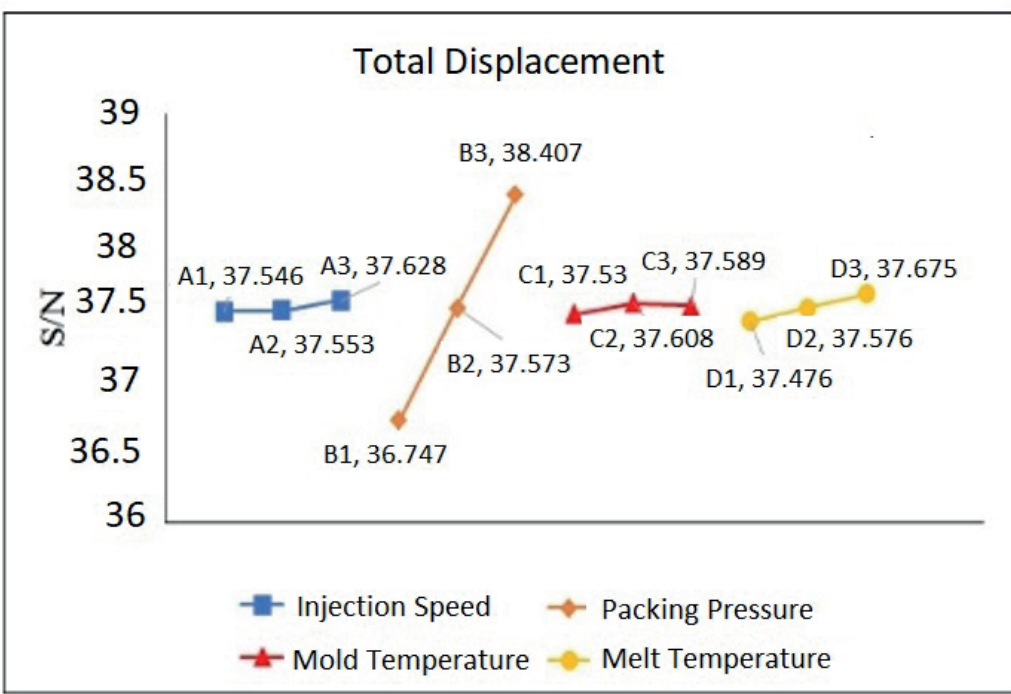

(b)

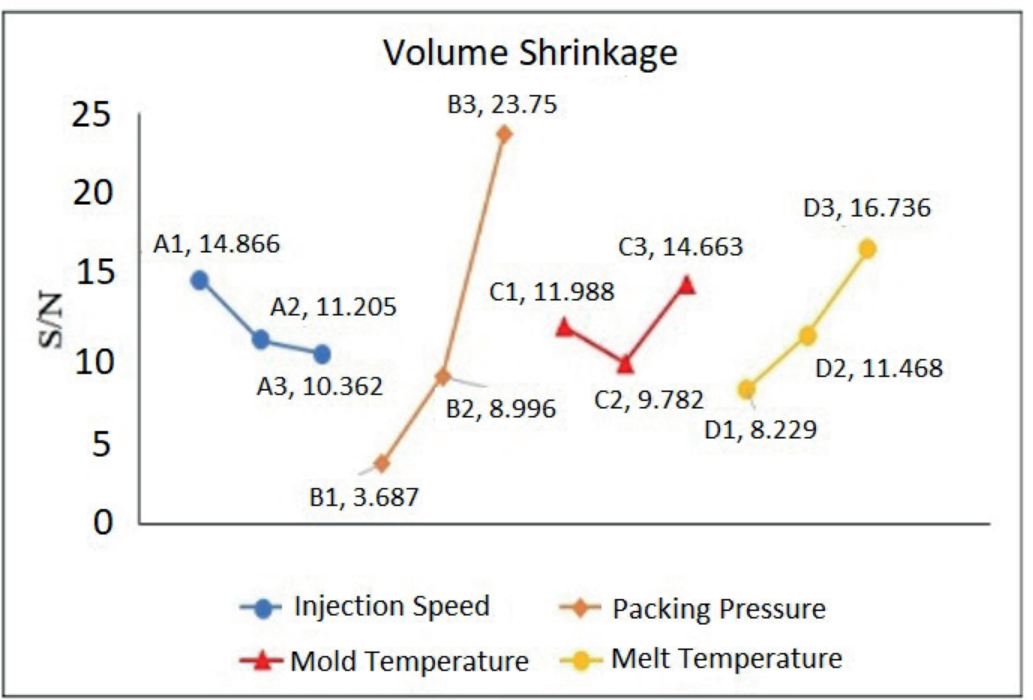

(c)

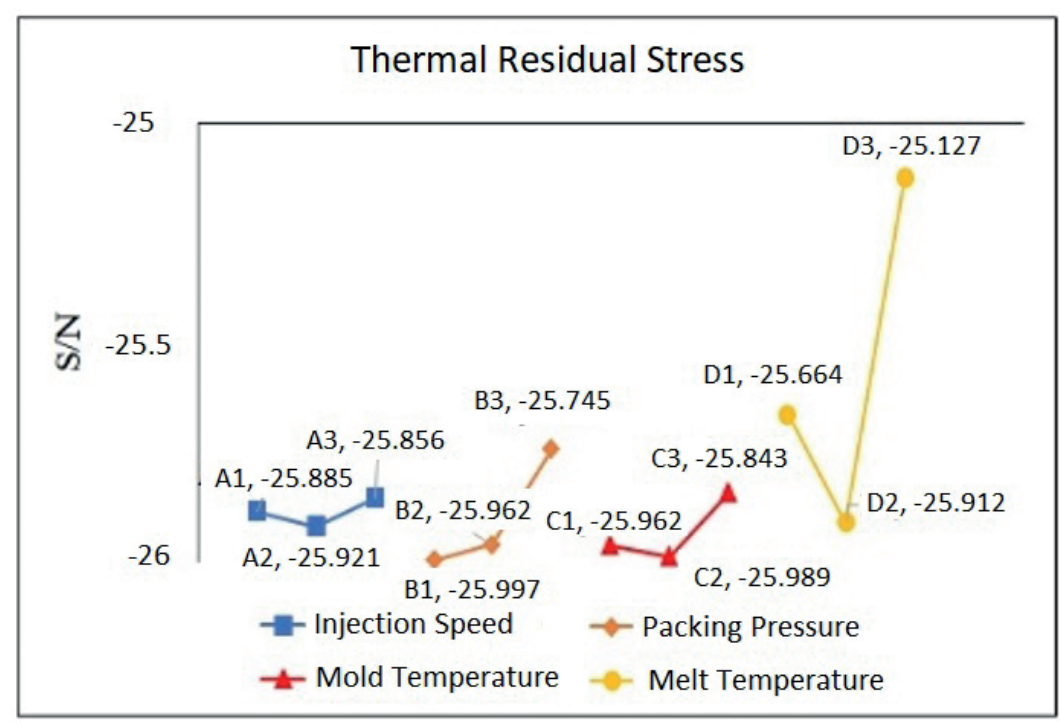

Fig. 9 Main effects S/N plot of Injection molding process 
For reducing the total displacement, Fig. 9 (a) shows that the packing pressure is the most important factor. The higher packing pressure applied (higher $\mathrm{S} / \mathrm{N}$ ) the smaller total displacement is achieved. Other factors such as injection speed, melt temperature and mold temperature have insignificantly effect on reducing the total displacement.

\subsubsection{The shrinkage}

Usually, packing pressure (holding pressure) is reversely proportional to shrinkage as shown in Fig. 10.

In this study, according Fig. 9 (b), packing pressure influences the most on volumetric shrinkage because of the biggest difference of signal to noise ratio. The higher packing pressure (high $\mathrm{S} / \mathrm{N}$ ), the smaller volumetric shrinkage can be achieved. After the melted polymer injected into the cavity, the temperature difference between the melt and the mold will cause the melt to cool and shrink quickly. Therefore, more polymer material needs to be filled into the cavity to continuously compensate the shrinkage. If the packing pressure is low, less material is injected into the cavity. This leads to a high shrinkage.

Injection speed (injection rate) also lead a considerable role in the influence on shrinkage. The relationship injection speed and shrinkage curve as shown in Fig. 11.

If the injection speed is too low, the melted polymer will be cooled before the cavity is completely filled. Therefore, the shrinkage will be higher. In contrast, if the cavity is filled with too high injection speed, the shear heating effect will cause the melt to increase its temperature and increase the shrinkage after cooling. Fig. 9 (b) shows that the shrinkage is increased when the injection speed increases. Therefore, a lower injection speed should be chosen.

Shrinkage and melt temperature present a U-shaped curve. That means the shrinkage becomes higher at both low and high melt temperature (Fig. 12).

At low melt temperature, the high viscosity will resist the flow to inject into the cavity. The pressure gradient at the gate and at the end of the flow will be high. Hence, shrinkage will be increased. At comparatively high melt temperature, the high shrinkage is as an inherent result in temperature change. In Fig. 9 (b), the shrinkage is reduced with the higher melt temperature corresponding to high signal to noise ratio.

Mold temperature also has influence on the shrinkage. It can be seen in the Fig. 9 (b) that at $90{ }^{\circ} \mathrm{C}$ the signal to noise ratio is the highest. That means the shrinkage is minimum.

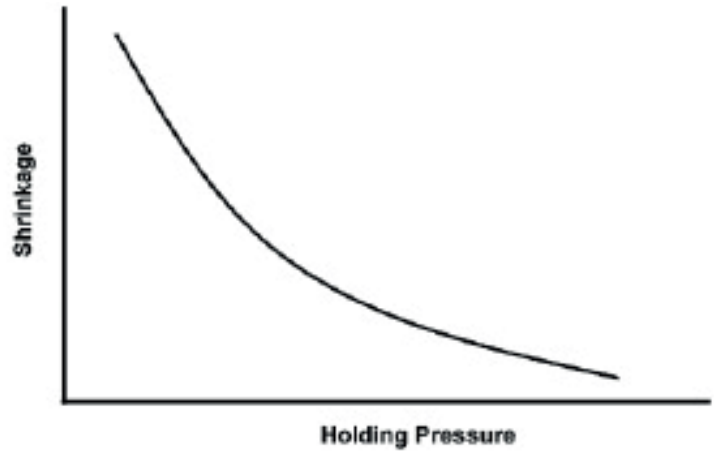

Fig. 10 The relationship between shrinkage and packing pressure [19]

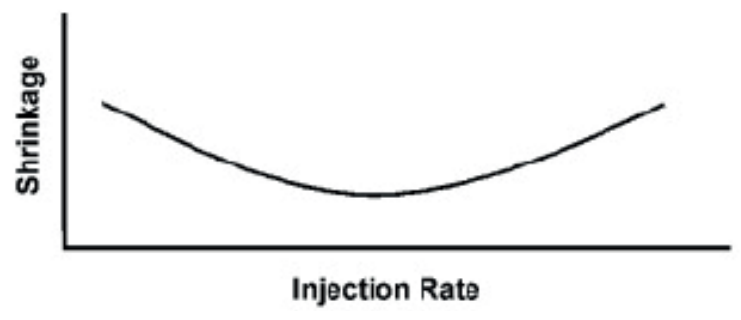

Fig. 11 The relationship between injection rate and shrinkage [19]

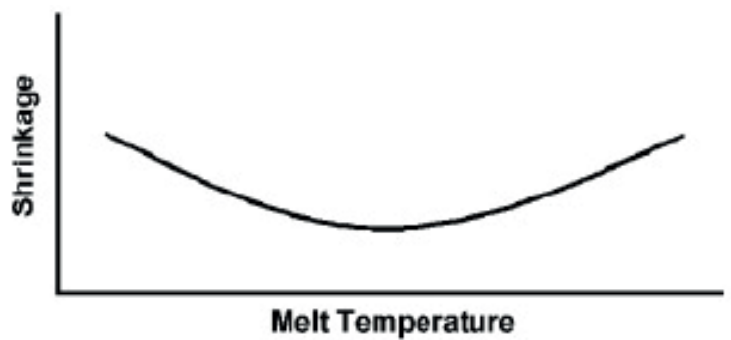

Fig. 12 Melt temperature and shrinkage curve [19]

\subsubsection{The thermal residual stress}

According to the response Fig. 9 (c), it can be seen that the melt temperature has the highest influence on reducing thermal residual stress. The higher melt temperature, the more residual stress is generated. The packing pressure also considerably affects the residual stress. If the packing pressure becomes higher, the residual stress will become smaller. On the other hand, both injection speed and mold temperature have not too much effect on residual stress.

\subsection{Grey relational analysis}

\subsubsection{Grey relational analysis}

Step 1 Normalize the original data

Instead of calculating the $\mathrm{S} / \mathrm{N}$ ratio first, the quality values are normalized directly. Table 10 shows the normalized values of three quality characteristics.

Step 2 Calculate the Grey relational coefficient and Grey grade 
After normalizing the values of three quality characteristics, the Grey relational coefficient and Grey grade are calculated. Grey relational coefficients represent the correlation between the desired and actual experimental data. Then the Grey grades are the averages of the coefficients of all factors and are shown in Table 10. For example, the summation of the three normalized S/Ns for trial 3 is $2.490(=1+1+0.490)$, so the Grey grade for experiment 1 is 0.830 , that is $2.490 / 3$.

Step 3 Select the optimum factor/ level combination

The main effect of each factor on all of the quality characteristics is shown in Table 11.

The higher Grey relational grade provides the better product quality. Therefore, based on Table 11, the optimal factor/level combination is $\mathrm{A} 3 \mathrm{~B} 3 \mathrm{C} 3 \mathrm{D} 1$ and the values of the factors are injection speed $(300 \mathrm{~mm} / \mathrm{sec})$, packing pressure $(90 \mathrm{MPa})$, mold temperature $\left(90{ }^{\circ} \mathrm{C}\right)$, and melt temperature $\left(270^{\circ} \mathrm{C}\right)$.

Based on the optimal factor/level combinations, the confirmatory experiments were performed. The resulting $\mathrm{S} / \mathrm{N}$ ratio of the quality values can be seen in Table 12 . The sum of $\mathrm{S} / \mathrm{N}$ in the experiment that applied the optimal factor/level combination is 29.598 .

\subsubsection{The influence of four factors on the objective quality characteristics}

Due to the difficulties in optimizing many quality characteristics simultaneously with Taguchi experimental method, so Grey relational analysis (GRA) was implemented in this experiment. GRA has been performed to turn three quality outputs into one single characteristic in this study. The single characteristic can be considered as a compromise between three quality outputs. By computing the Grey relational grade, the influence of injection molding parameters on the quality outputs has been investigated.

As can be seen, in the Grey grade Table 11 and Fig. 13, the corresponding factors at experiment 9 has the highest Grey grade and the best result among the 9 runs. Packing pressure is the most significant factor that affects the three quality characteristics at the same time, while injection speed, mold and melt temperature affect the multi-objective characteristics slightly.

\subsubsection{Analysis of variance (ANOVA)}

The contributions of the factors are packing pressure $95 \%$, mold temperature $2.24 \%$, melt temperature $1.57 \%$, and injection speed $0.78 \%$ as shown in Table 13. Packing

Table 10 Grey relational analysis

\begin{tabular}{|c|c|c|c|c|c|c|c|}
\hline \multirow[t]{2}{*}{ Exp. } & \multicolumn{3}{|c|}{ Normalized S/N Ratio Values } & \multicolumn{3}{|c|}{$\begin{array}{l}\text { Grey Relational Coefficient of Normalized } \\
\text { S/N Ratio Values }\end{array}$} & \multirow[t]{2}{*}{ Grade } \\
\hline & $\mathrm{TD}(\mathrm{mm})$ & VS (\%) & TRS (MPa) & $\mathrm{TD}(\mathrm{mm})$ & VS (\%) & TRS (MPa) & \\
\hline 1 & 0.000 & 0.000 & 0.591 & 0.333 & 0.333 & 0.550 & 0.405 \\
\hline 2 & 0.551 & 0.533 & 0.410 & 0.527 & 0.517 & 0.459 & 0.501 \\
\hline 3 & 1.000 & 1.000 & 0.479 & 1.000 & 1.000 & 0.490 & 0.830 \\
\hline 4 & 0.162 & 0.269 & 0.000 & 0.374 & 0.406 & 0.333 & 0.371 \\
\hline 5 & 0.493 & 0.403 & 0.684 & 0.496 & 0.456 & 0.613 & 0.522 \\
\hline 6 & 0.930 & 0.921 & 0.503 & 0.877 & 0.864 & 0.501 & 0.747 \\
\hline 7 & 0.138 & 0.154 & 0.469 & 0.367 & 0.372 & 0.485 & 0.408 \\
\hline 8 & 0.604 & 0.676 & 0.098 & 0.558 & 0.607 & 0.357 & 0.507 \\
\hline 9 & 0.954 & 0.807 & 1.000 & 0.916 & 0.722 & 1.000 & 0.879 \\
\hline
\end{tabular}

Table 11 Main effect of the four factors on quality characteristics

\begin{tabular}{lcccc}
\hline & Injection Speed & Packing Pressure & Mold Temperature & Melt Temperature \\
\hline Level 1 & 0.579 & 0.395 & 0.553 & 0.602 \\
Level 2 & 0.547 & 0.510 & 0.584 & 0.552 \\
Level 3 & 0.598 & 0.819 & 0.587 & 0.569 \\
Difference & 0.051 & 0.424 & 0.034 & 0.050 \\
\hline
\end{tabular}

Table $12 \mathrm{~S} / \mathrm{N}$ ratio of the quality values in optimal factor/level combinations

\begin{tabular}{|c|c|c|c|c|c|c|c|}
\hline \multirow{2}{*}{$\begin{array}{l}\text { Factor } \\
\text { Combination }\end{array}$} & \multicolumn{3}{|c|}{ Quality Values } & \multicolumn{3}{|c|}{$\mathrm{S} / \mathrm{N}(\mathrm{dB})$} & \multirow{2}{*}{ Sum of $\mathrm{S} / \mathrm{N}(\mathrm{dB})$} \\
\hline & $\mathrm{TD}(\mathrm{mm})$ & VS (\%) & TRS(MPa) & $\mathrm{TD}(\mathrm{mm})$ & VS (\%) & TRS(MPa) & \\
\hline A3B3C3D1 & 0.01182 & 0.15401 & 18.186 & 16.249 & 38.544 & -25.195 & 29.598 \\
\hline
\end{tabular}




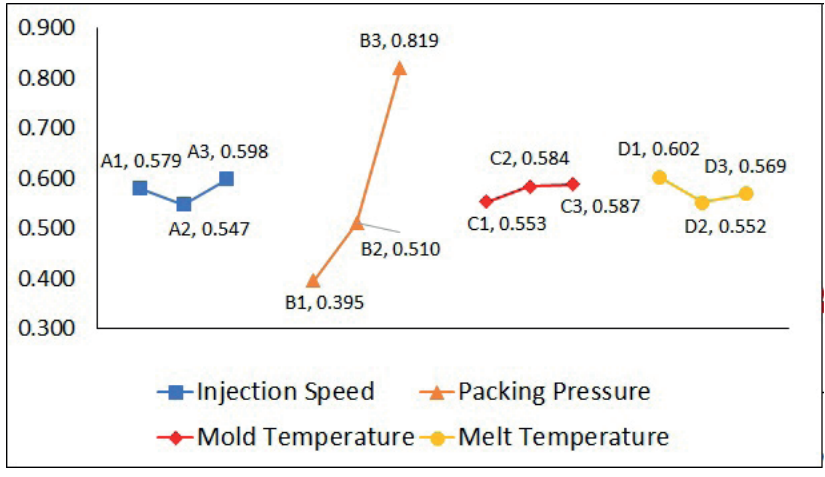

Fig. 13 Factors effect on Grey grade value

pressure is the dominant factor in the molding of this micro LED lens. If we take a look at the mold layout in Fig. 4 again, we can see the total volume of the cavities is $225.736 \mathrm{~mm}^{3}$ and the total injection volume, cavities and runner system, is $2101.932 \mathrm{~mm}^{3}$, only the last $10 \%$ of the injection stroke is for inject the melt to the cavities, the melt pressure decreases gradually when it travels through nozzle, runner, gate, and then finally fills the cavities at lower pressure, so higher packing pressure is required to push more melt into the cavities, and packing pressure becomes the most dominant factor in molding this lens.

\subsection{Optimal levels of injection molding parameters}

After calculating the Grey relational grades, we can find out the optimal levels of four factors. For each factor, the optimal value presents the highest Grey relational grade. Therefore, based on the plots in Fig. 13 the optimum parameters of each factor are injection speed at level $3(300 \mathrm{~mm} / \mathrm{sec})$, packing pressure at level $3(90 \mathrm{MPa})$, mold temperature at level 3 $\left(90^{\circ} \mathrm{C}\right)$, and melt temperature at level $1\left(270{ }^{\circ} \mathrm{C}\right)$.

For this optimal molding condition, the molding simulation was performed again. The molding simulation results are shown in Figs. 14, 15 and 16.

The quality values in the confirmatory experiment are average total displacement $0.0118247 \mathrm{~mm}$, volumetric shrinkage $0.15401 \%$, and thermal residual stress 18.1858 MPa.

The Grey relational grade was calculated again as well to verify whether the quality results of the optimal parameter combination are the best or not. In the case of this combination (A3B3C3D1), the Grey relational grade is 0.912 and it's better than the grades of the experiments in Table 10. Moreover, we can observe that the three quality characteristics of this combination are the best in all 10 trials as well. That means the product quality is improved.

Table 13 Analysis of variance

\begin{tabular}{|c|c|c|c|c|c|}
\hline Parameter & DOF & Sum of Squares & Mean of Variance & $\mathrm{F}$ & $\mathrm{P}(\%)$ \\
\hline Injection Speed (InS) & 2 & 0.002 & 0.001 & 0.002 & 0.78 \\
\hline Packing Pressure $\left(P_{\text {Press }}\right)$ & 2 & 0.244 & 0.122 & 0.244 & 95.31 \\
\hline Mold Temperature $\left(T_{\text {mold }}\right)$ & 2 & 0.006 & 0.003 & 0.006 & 2.34 \\
\hline Melt Temperature $\left(T_{\text {melt }}\right)$ & 2 & 0.004 & 0.002 & 0.004 & 1.57 \\
\hline Error & & & & & 0 \\
\hline Total & 8 & 0.256 & & & 100 \\
\hline
\end{tabular}
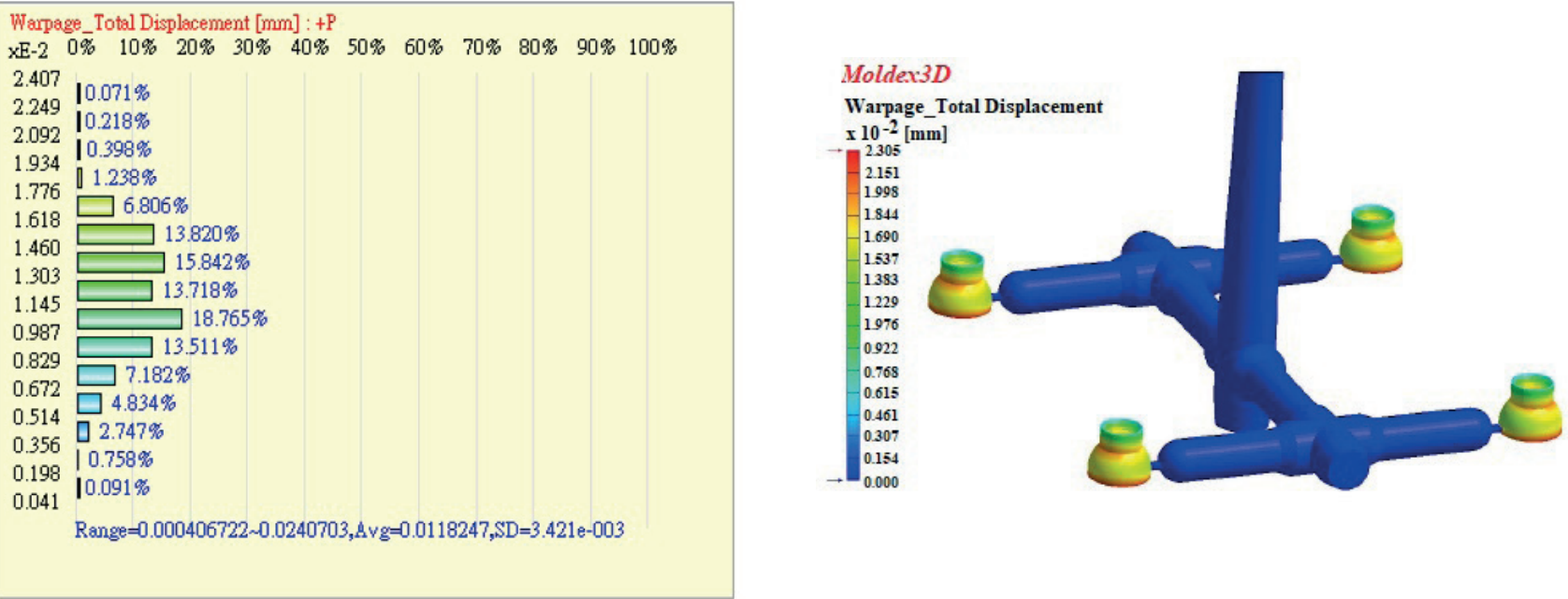

Fig. 14 Total displacement value of the optimal molded part 

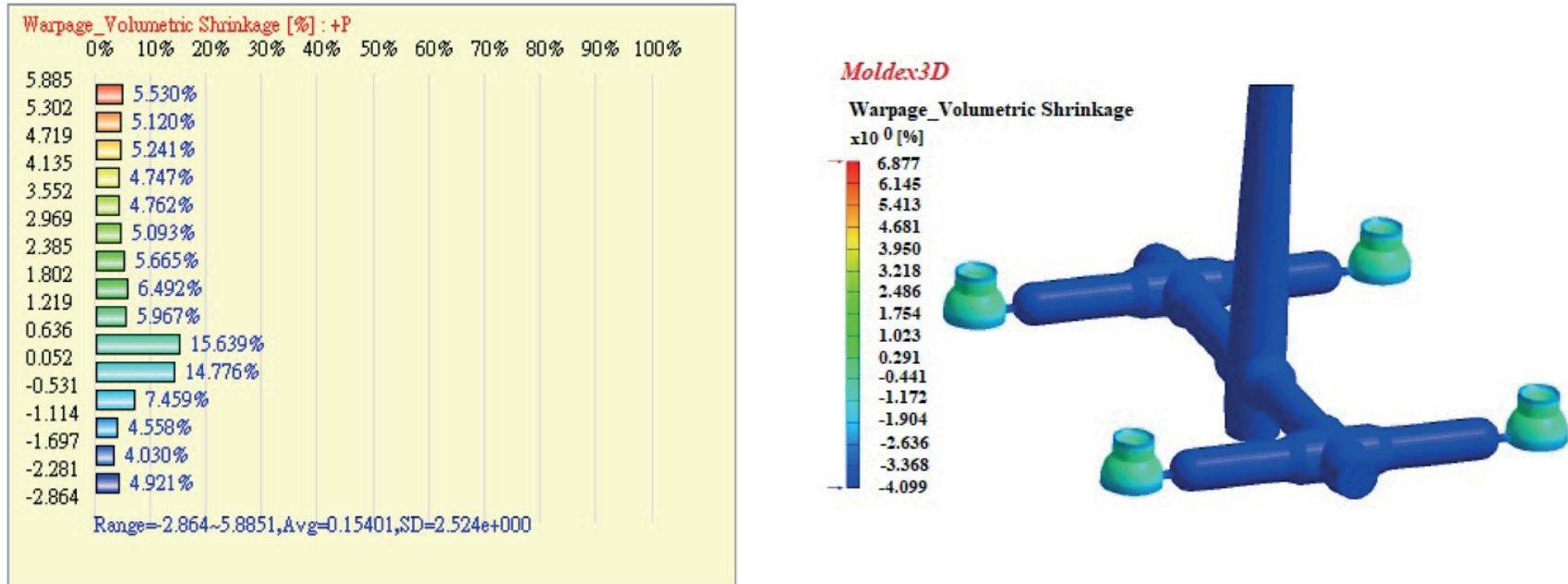

Fig. 15 Volumetric shrinkage value of the optimal molded part
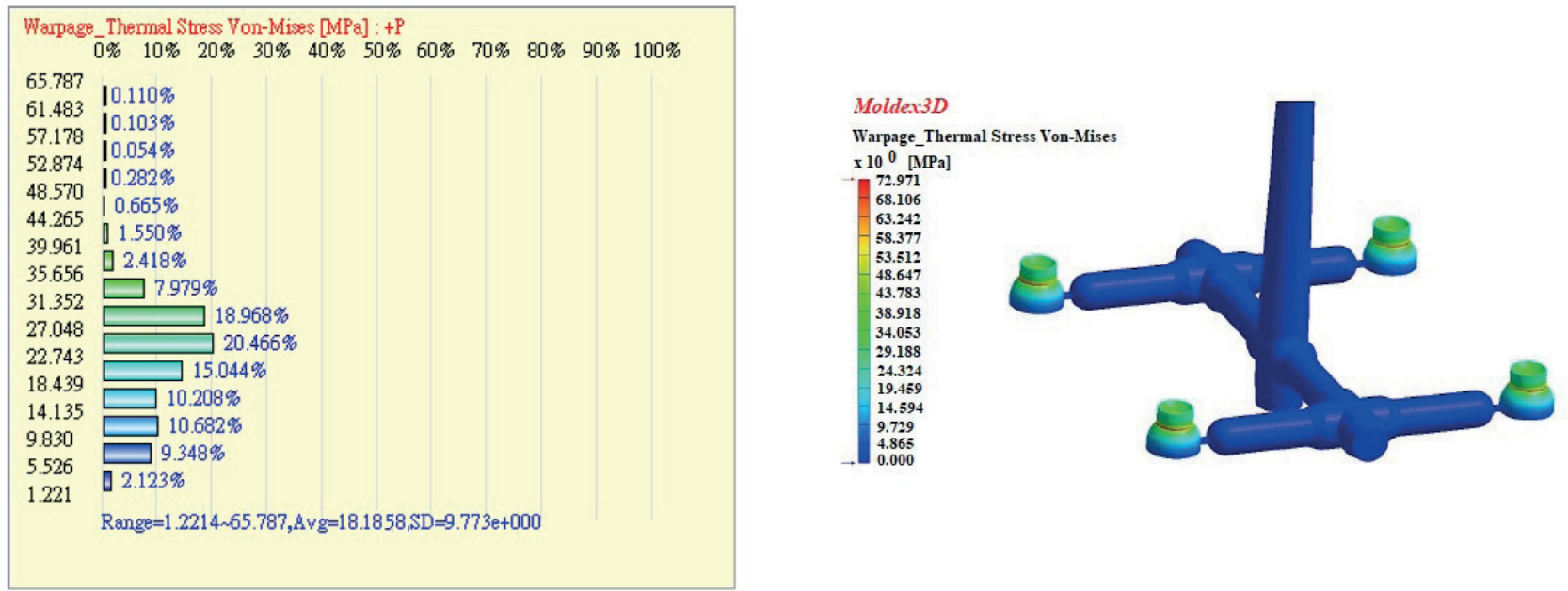

Fig. 16 Total thermal residual stress value of the optimal molded part

\section{Optical verification}

After finding out the optimal molding parameter combination, a new simulation of molding process has been performed again to check the final shape and dimension of the lens. According to the final molding simulation, the dimensions of the lens have been estimated and rebuilt. TracPro has been used to verify the optical performance. In the mold filling simulation, some observation nodes have been set to measure the overall dimension of the lens. Each node has specific values of X, Y, Z. So, based on the node coordinates after molding, the new lens model is rebuilt. Fig. 17 shows the nodes set in the molded part.

The overall dimensions of the lens have been determined by computing the distance of the nodes in the coordinate system. Therefore, we obtain the new dimensions of $\mathrm{A}, \mathrm{B}$, and $\mathrm{C}$. These overall dimensions are shown in Table 14 and are used to build the lens model.

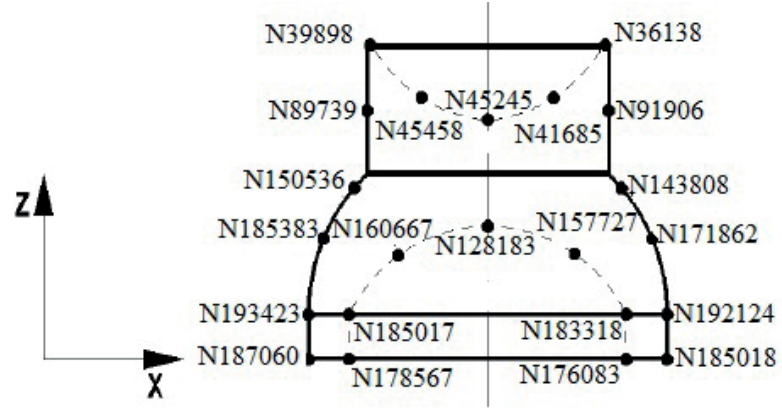

Fig. 17 Node setting in the molded part

The optical simulation was implemented by using TracePro software again with the same simulation conditions described in previous section except the geometry of the lens. The luminance uniformity and viewing angle have also been calculated according to the Eq. (1) and Eq. (2). The rectangular and polar luminance distribution 
Table 14 New dimensions of the lens

\begin{tabular}{llllll}
\hline $\mathrm{A}$ & $\mathrm{B}$ & $\mathrm{C}$ & $\mathrm{D}$ & $\mathrm{E}$ & $\mathrm{F}$ \\
\hline 0.665816 & 4.79212774 & 3.879613 & 2.6 & 3.03 & 2.43 \\
\hline
\end{tabular}

are shown in Figs. 18 and 19. After simulation, the viewing angle is $124.76^{\circ}$ and the luminance uniformity is $92.61 \%$. Since it is not possible to complete duplicate the shape of the cavity with the total displacement and shrinkage during molding, the qualities of the molded lens degrade a little bit from original $129.2^{\circ}$ in viewing angle and $94.14 \%$ in uniformity.

\section{Conclusions}

There is always defects and not possible to duplicate the cavity shape perfectly in the molding process, how to minimize the defects and achieve the best molding quality is one of the big concerns in this industry. Using Grey relational analysis and analysis of variance, this study investigated the effect of injection molding parameters on the multi-response quality characteristics consist of total displacement, volumetric shrinkage, and thermal-induced residual stress using mold filling simulation technology. With the optimal parameters combination, the molded LED lens studied can achieve both high viewing angle $\left(124.76^{\circ}\right)$ and high luminance uniformity (92.61\%).

Packing pressure is the lone significant factor in this optimal process since the lens is so small and takes only $10 \%$ of the injection volume with the 50 -tonnage molding machine. There is a trend of using micromolding machine to mold parts small in volume and with parts with microstructures. To get better molding quality, further molding of this micro lens using micromolding machine can be considered.

\section{Acknowledgement}

This work is supported by the National Science Council (NSC) Taiwan under the grant of NSC 101-2221-E-151 -019. The financial support is acknowledged.

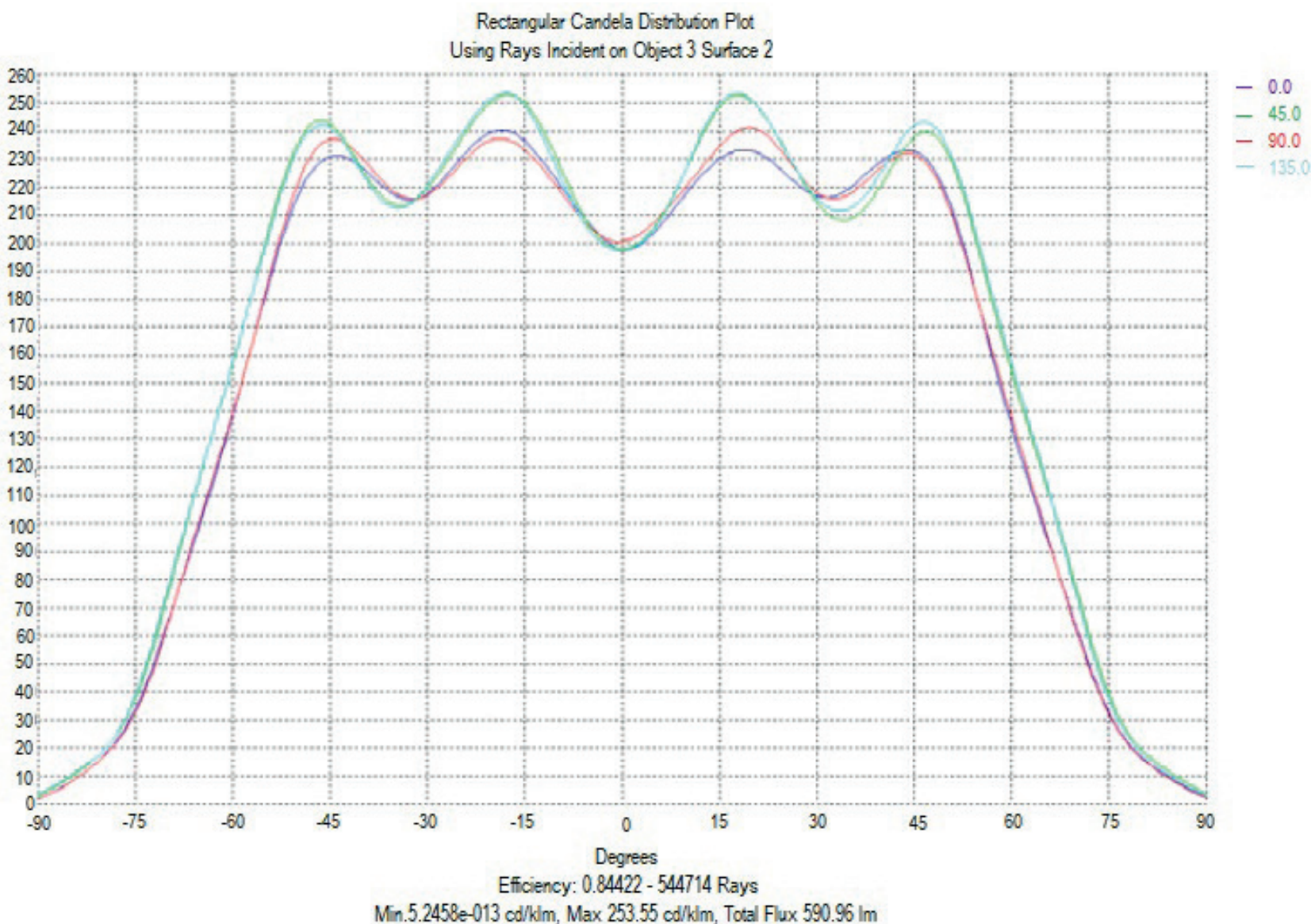

Fig. 18 Rectangular luminance distribution of the new lens 


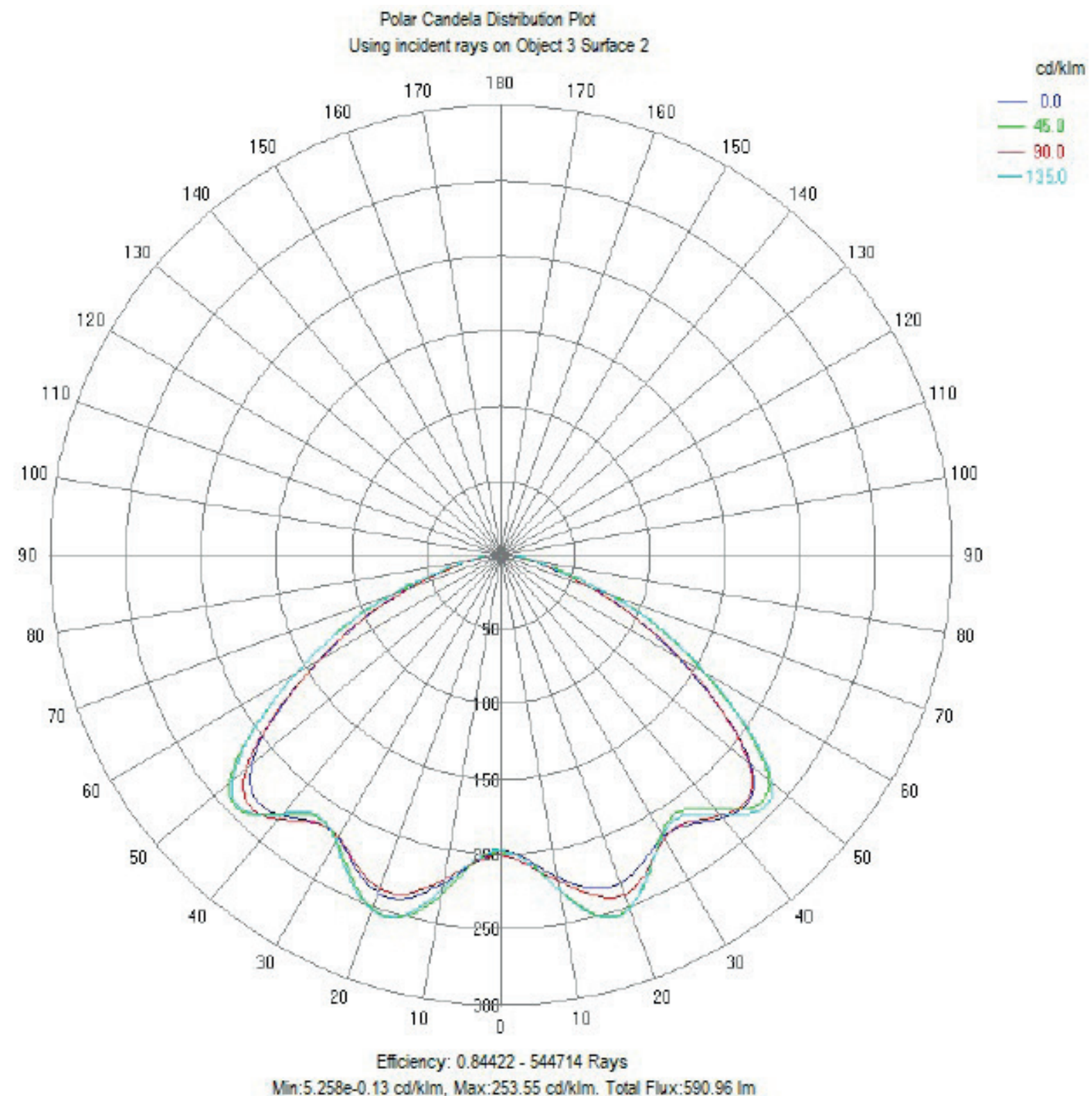

Fig. 19 Polar luminance distribution of the new lens

\section{References}

[1] Kovacs, J. G., Bercsey, T. "Influence of mold properties on the quality of molded parts", Periodica Polytechnica Mechanical Engineering, 49(2), pp. 115-122, 2005.

[2] Erzurumlu, T., Ozcelik, B. "Minimization of warpage and sink index in injection-molded thermoplastic parts using Taguchi optimization method", Materials and Design, 27(10), pp. 853-861, 2006. https://doi.org/10.1016/j.matdes.2005.03.017

[3] Tang, S. H., Tan, Y. J., Sapuan, S. M., Sulaiman, S., Ismail, N., Samin, R. "The use of Taguchi method in the design of plastic injection mould for reducing warpage", Journal of Materials Processing Technology, 182(1-3), pp. 418-426, 2007. https://doi.org/10.1016/j.jmatprotec.2006.08.025
[4] Wang, M.-W., Chen, C.-H., Arifin, F., Lin, J.-J. "Modeling and Analysis of Multi-shot Injection molding of Blu-ray objective lens", Journal of Mechanical Science and Technology, 32(10), pp. 4839-4849, 2018.

https://doi.org/10.1007/s12206-018-0932-z

[5] Kuo, C.-F. J., Su, T.-L. "Optimization of multiple quality characteristics for polyether ether ketone injection molding process", Fibers and Polymers, 7(4), pp. 404-413, 2006.

https://doi.org/10.1007/BF02875773

[6] Kitayama, S., Yamazaki, Y., Takano, M., Aiba, S. "Numerical and experiment investigation of process parameters optimization in plastic injection molding using mullti-criteria decision making", Simulation Modelling Practice and Theory, 85, pp. 1-18, 2018. https://doi.org/10.1016/j.simpat.2018.04.004 
[7] Lee, R. E., Hasanzadeh, R., Azdast, T. "A Multi criteria decision analysis on injection molding of polymeric microcellular nanocomposite foams containing multi-walled carbon nanotubes", Plastics, Rubber and Composites Macromolecular Engineering 46(4), pp. 1-8, 2017.

https://doi.org/ 10.1080/14658011.2017.1300210

[8] Haq, A. N., Marimuthu, P., Jeyapaul, R. "Multi response optimization of machining parameters of drilling $\mathrm{Al} / \mathrm{SiC}$ metal matrix composite using grey relational analysis in the Taguchi method", The International Journal of Advanced Manufacturing Technology, 37(3-4), pp. 250-255, 2008.

https://doi.org/ 10.1007/s00170-007-0981-4

[9] Tzeng, C. J., Lin, Y. H., Yang, Y.-K., Jeng, M.-C. "Optimization of turning operations with multiple performance characteristics using the Taguchi method and Grey relational analysis", Journal of Materials Processing Technology 209(6), pp. 2753-2759, 2009. https://doi.org/10.1016/j.jmatprotec.2008.06.046

[10] Panda, A., Sahoo, A. K., Rout, A. K. "Multi-attribute decision making parametric optimization and modeling in hard turning using ceramic insert through grey relational analysis: A case study", Decision Science Letters, 5, pp. 581-592, 2016. https://doi.org/ 10.5267/j.dsl.2016.3.001

[11] Sofuoglu, M. A. "Hybridizing Taguchi algorithm with ideal method to solve machining problems", International Journal of Intelligent Systems and Application in Engineering, 5(2), pp. 64-69, 2017. https://doi.org/10.18201/ijisae.2017528730

[12] Sofuoglu, M. A., Orak S. "A Novel Hybrid Multi Criteria Decision Making Model: Application to Turning Operations", International Journal of Intelligent Systems and Applications in Engineering, 5(3), pp. 124-131, 2017. https://doi.org/10.18201/ijisae.2017531427

[13] Sofuoglu, M. A., Arapoglu R. A., Orak S. "Multi Objective Optimization of Turning Operation Using Hybrid Decision Making Analysis", Anadolu University Journal of Science and Technology A-Applied Sciences and Engineering, 18(3), pp. 595-610, 2017. https://doi.org/10.18038/aubtda.287801
[14] Sivam, S. P. S. S., Karupppaiah, S. M., Yedida, B. K., Atluri, J. R., Mathur, S. "Multi Response Optimization of Setting Input Variables for Getting Better Product Quality in Machining of Magnesium AM60 by Grey Relation Analysis and ANOVA", Periodica Polytechnica Mechanical Engineering, 62(2), pp. 118-125, 2018. https://doi.org/10.3311/PPme.11034

[15] Sivam, S. P. S. S., Saravanan, K., Pradeep, N., Moorthy, K. S., Rajendrakumar, S. "Grey Relational Analysis and Anova to Determine the Optimum Process Parameters for Friction Stir Welding of Ti and Mg Alloys", Periodica Polytechnica Mechanical Engineering, 62(4), pp. 1-7, 2018. https://doi.org/3311/PPme.12117

[16] Chen, W.-C., Lai, T.-T., Wang, M.-W., Hung, H.-W. "An optimization system for LED lens design", Expert Systems with Applications, 38(9), pp. 11976-11983, 2011. https://doi.org/ 10.1016/j.eswa.2011.03.092

[17] Altan, M. "Reducing shrinkage in injection moldings via the Taguchi, ANOVA and neural network methods", Materials and Design, 31(1), pp. 599-604, 2010. https://doi.org/10.1016/j.matdes.2009.06.049

[18] Oktem, H., Erzurumlu, T., Uzman, I. "Application of Taguchi optimization technique in determining plastic injection molding process parameters for a thin-shell part", Materials and Design, 28(4), pp. 1271-1278, 2007. https://doi.org/10.1016/j.matdes.2005.12.013

[19] Fischer, J. M. "Handbook of Molded Part Shrinkage and Warpage", 2nd ed., William Andrew Inc., The Boulevard, Langford Lane, Kidlington, Oxford, OX5 1GB, UK, 2013. 